\title{
EL INFLUJO DE LA LENGUA \\ PORTUGUESA SOBRE EL MALAYO
}

ROBERT K. BOWLES

Professor de Espanhol

Fac. Ponta Grossa

En 1511 la escuadra de António de Abreo, integrada por tres buques, llegó a Banda, una de las islas Molucas (Archipiélago Indio), donde fue establecida una colonia portuguesa. Francisco Serrão, quien mandaba uno de los navios, alejándose cada vez más de los otros y acabando por desembarcar en la isla de Amboina, al final hizo rumbo a Ternate. Allí consiguió adquirir el monopolio para la venta de clavos y obtuvo igualmente permiso de edificar una fortaleza, cuya construcción no concluyó sino muchos años más tarde, cuando Jorge de Castro era gobernador. Le pusieron a la misma el nombre de Nossa Senhora do Rosário. Entonces también empezaron a levantarse fuertes en las islas de Amboina y Tidore, hecho que dio comienzo a la heguemonía de los portugueses en el Archipiélago Indio. Basta realzar solamente estos datos, ya que una exposición de los acontecimientos históricos ulteriores me llevaría demasiado lejos del propósito de dar al lector una idea inmediatamente concebible de lo que sugiere el título de esta breve disertación. Importa, pues, saber dónde y hasta qué punto la lengua lusa haya dejado huellas en el malayo que ya desde hace alguns siglos puede ser considerado como el vehículo o bien como la lengua franca por excelencia de las diversas agrupaciones étnicas de Insulindia. Se me antoja que la estructura del malayo no ha llegado de ningún modo a ser afectada, lo que entre otras causas talvez sea explicable por su índole aglutinante. En el léxico, en cambio, se han ido introduciendo unas decenas de vocablos extraños, todos ellos frutos del contacto y convivencia de durante siglo y medio con los portugueses. La lista que sigue a continuación y que constituye de ello una prueba elocuente contiene exclusivamente aquellas voces cuya etimología se deja determinar con suficiente seguridad. Por consiguiente no están 
consignados aquí los casos referente a los cuales aun estoy en duda, mientras que serán tampoco mencionados los vocablos no comúnmente usados en los territorios en que el malayo que ya desde hace algunos siglos puede ser considerado tendido. Las islas Molucas, verbigracia, pudieran mostrarnos unos rasgos bastante arcaicos a este respecto. Sirva de ejemplo la palabra "tartaruga" que debe haberse conservado allí. Huelga decir que, para un estudio más detenido sobre el particular, hay que tener en cuenta el factor cronológico, el grado de infiltración social y la circunstancia de que el objeto apetecido por los lusos era esencialmente comercial y que su poderío estribaba mayormente en la posesión de puntos de apoyo estratégicos situados a orillas del mar.

La ortografía del malayo usada hoy en dia casi no difiere de la que era oficialmente adoptada en las antiguas Indias Orientales Holandesas. Como se sabe, a la dominación portuguesa le sucedió, através de una serie de episodios de lucha, la de los bátavos, pueblo que por largo lapso de tiempo sabía mantenerse firme en aquella parte de Asia. A raíz de la proclamación de la independencia de Indonesia el gobierno de la nueva nación pasó a implantar algunas insignificantes reformas ortográficas, de las cuales la más oportuna es sin duda la abolición de la agrupación oe (tomada de la ortografía neerlandesa) equivalente al sonido $u$ en portugués y español. Actualmente dicho sonido en malayo se ve simbolizado por la letra $u$.

Para la pronunciación de las palabras malayas que constan aquí abajo me ha parecido conveniente dar indicaciones acerca de aquellas letras que podrian ofrecer alguna dificultad. En contra, he pasado por alto los caracteres representantes de sonidos aproximadamente iguales a los conocidos en las dos lenguas arriba apuntadas. En la mayoría de los casos la e tónica en posición libre tiende a cerrada y se prolonga un poco, al paso que la e tónica en posición trabada tiende a abierta con poca duración. Sin embargo las dos no se alejan mucho de su fase intermediaria de abertura. La e átona se pronuncia más o menos como la e de "tenir" en francés o de "bestimmt" en alemán; nj representa nh en portugués y $\tilde{\mathrm{n}}$ en español; dj es una d palatalizada casi no africada $y$ tj una $t$ palatalizada ligeramente africada; $n g$ 
posee el mismo timbre que ng de "long" en inglés o "lang" en alemán.

En las voces malayas subsiguientes el acento tónico recae en la penúltima sílaba. Se exceptúan en esta lista tan sólo la esdrújula "paderi" y las agudas "beledu", "kerpus", "Natal" y "tjepiau". La i de "rial" y "tjepiau" se encuentra en hiato.

Consideremos ahora las etimologías:

portugués

alavanca

arruda

bandeira

bola

bomba

boneca

camisa

carapuça

carrêta

chinela

escola

festa

fita

igreja

janela

lanterna

manteiga

mesa

pantalonas

pena

pipa

prata

renda

roda

ronda

ronda

sela

tenda

tinta

toalha malayo

alabangka

aruda

bendera

bola

bomba

boneka

kemedja

kerpus

kereta

tjenela

sekola (h)

pesta

pita

geredja

djendela

lentera

mentega

medja

tjelana

pena

pipa

perada

renda

roda

ronda

peronda

sela

tenda

tinta

tuala signif. de la palabra malaya

palanca

ruda

bandera extranjera

pelota, bola

bomba (de incendio)

muñeca (juguete)

camisa

gorro (de dormir)

coche, carruaje

chinela

escuela

fiesta

cinta

iglesia

ventana

linterna

manteca

mesa

pantalón

pluma para escribir

barrica, pipa

hoja de oro batido

encaje, randa

rueda

patrullar

patrulla

silla de montar

toldo, tienda

tinta

toalla, servilleta 


\begin{tabular}{lll} 
portugués & malayo & signif. de la palabra malaya \\
armário & lemari & armario \\
armário & almari & armario \\
caldo & kaldu & caldo \\
coelho & terwelu & conejo \\
dado & dadu & dado \\
domingo & hari minggu & domingo \\
falso & palsu & falso \\
garfo & garpu & tenedor \\
guardo & gardu & garita \\
inteiro & antero & entero \\
martelo & martil & martillo \\
queijo & kedju & queso \\
sapato & sepatu & zapato \\
soldado & serdadu & soldado \\
tempo & tempo(h) & tiempo (cron.) \\
trigo & terigu & trigo \\
tronco & terongko & prisión, cárcel \\
veludo & belud (r) u & terciopelo \\
veludo & beledu & terciopelo \\
alfinête & peniti & alfiler \\
couve & kubis & col \\
padre & paderi & sacerdote, padre \\
botão & butang & botón para vestido \\
cotão & kutang & corpiño, justillo \\
leilão & lelang & subasta, almoneda \\
morrão & murang & mechón \\
pão & paung & bizcocho, pan \\
chapéu & tjepiau & chacó, sombrero \\
dedal & bidal & dedal \\
Natal & Hari Natal & Pascua de Navidad \\
real & rial & real (subst.) \\
feitor & petor & administrador \\
mandador & mandor & capataz \\
senhor & sinjo & señorito, mestizo \\
traidor & teledor & moroso en el trabajo, \\
algoz & & traicionero (invectiva) \\
algoz & algodju & verdugo \\
& & verdugo \\
\hline
\end{tabular}


La voz "hari" que figura dos veces en la segunda columna significa "día".

Un estudio fonológico de aquellos vocablos malayos de la lista anterior en que se ha conservado el acento tónico original del portugués nos permite sacar algunas conclusiones:

\section{1 - Vocales tónicas:}

a se conserva en alabangka, perada, tuala, lemari, almari, kaldu, dadu, palsu, garpu, gardu, sepatu, serdadu, paderi, Natal y rial;

e se conserva en boneka, kereta, tjenela, pesta, geredja, djendela, lentera, medja, pena, renda, sela, tenda, terwelu y tempo $(\mathrm{h})$;

e se hace i en peniti (de alfinête - pineti);

ei se hace e en bendera, mentega, antero y kedju;

eu se hace iau en tjepiau;

i se conserva en pita, pipa, tinta, minggu y terigu;

i se hace e en kemedja;

o se conserva en bola, bomba, sekola (h), roda, ronda, (me) ronda, peronda, terongko, algodja y algodju;

o se hace a en tjelana (de pantalonas - talona);

ou se hace $u$ en kubis;

u se conserva en aruda, kerpus y belud(r) $u$.

2 - Vocales postónicas finales:

a se conserva (véase la primera serie de palavras); (h);

a se conserva con ligera aspiración o sin ella en sekola

o se conserva con la ortografía de u (véase la segunda serie de palabras);

o se convierte de vocal cerrada en vocal más abierta escribiéndose 0 en antero y terongko;

o demuestra el mismo procedimiento pronunciándose con ligera aspiración o sin ella en tempo(h);

io se hace $i$ en lemari y almari;

e se hace $\mathrm{i}$ en peniti (véase el punto 1) y paderi;

e se hace is en kubis. 
3 - Vocales protónicas:

a se conserva en alabangka, aruda, almari, Hari Natal, algodja y algodju;

a se hace e en bendera, kemedja, kereta, djendela, lentera, mentega, lemari, sepatu y tjepiau, voz en que tje proviene de s mojada seguida de e;

a se diptonga haciéndose ie tras $t$ en tjelana (véase el punto 1);

a se pierde en kerpus (de carapuça);

e se conserva en belud(r) $u$;

i se hace a en antero;

i se hace e en tjenela y peniti (véase el punto 1);

i se pierde con la sílaba que integra en geredja (de igreja - gredja);

o se hace e en serdadu;

o se pierde con la sílaba de que forma parte en minggu.

4 - Vocales que preceden a las protónicas:

a se conserva en alabangka;

a se hace e en kerpus (véase el punto 3);

a se pierde con la sílaba de que forma parte en tjelana y peniti (véase para ambos vocablos el punto 1 ).

5 - Vocales en hiato:

rea se hace ria en rial;

toa se hace tua en tuala;

coe se hace twe en terwelu (de coelho - twelu);

gua se hace ga en gardu.

\section{6 - Consonantismo:}

f pierde su carácter fricativo convirtiéndose en consonante oclusiva $p$ en pesta, pita, palsu, garpu, peniti;

$\checkmark$ pierde su carácter fricativo convirtiéndose en consonante oclusiva $b$ en alabangka, belud $(r) \mathrm{u}$ y kubis;

j se hace dj en geredja, djendela y kedju; 
$s$ intervocálica se hace dj en kemedja y medja;

$z$ final se hace dj en algodja y algodju;

ch se hace tj en tjenela y tjepiau;

$\mathrm{k}$ se dentaliza haciéndose $\mathrm{t}$ en terwelu (véase el punto 5);

$t$ se sonoriza en perada;

lh se despalataliza en tuala y terwelu;

$r$ se confunde con l en lemari y almari;

rn sufre asimilación regresiva en lentera.

7 - Prótesis:

Ocurre en meronda y peronda (de ronda).

\section{8 - Epéntesis:}

Ocurre en sekola $(\mathrm{h})$ (de escola - skola $(\mathrm{h})$, geredja (véase el punto ), djendela (de janela - djenela), perada de prata - prada), terwelu (véase el punto 5), terigu (de trigo trigu), terongko (de tronco - trongko) y paderi (de padre - padri).

\section{9 - Paragoge:}

Ocurre en algodja y algodju, dobletes de algoz.

10 - Aféresis:

Ocurre en sekola $(\mathrm{h})$ (véase el punto 8), geredja (véase el punto 3), tjelana (véase el punto 1) y mingvu (de domingo).

\section{1 - Metátesis:}

Ocurre en lemari (de armário - almari).

Se produce dislocación regresiva del acento tónico en martil, butang, kutang, lelang, murang, bidal, petor, mandor, sinjo y teledor, todas ellas voces llanas. Tropezamos con dislocación progresiva del acento tónico en beledu, voz aguda.

En la quinta edición del Diccionario Malayo-Neerlandés y Neerlandés-Malayo del prof. Ph. S. van Ronkel (Universidad de Leyde) del año de 1946, del cual no sé si existe otra 
posterior, las voces malayas provenientes del portugués van acompañadas de la indicación "Port.". No se nos brinda, empero, con las respectivas etimologías, lo que no dejaría de ser de cierta utilidad. Basándome en los datos de este artículo quisiera señalar la ausencia de dicha indicación en los vocablos "alabangka, bola, bomba, kerpus, sekola(h), tjelana, pena, pipa, kubis, butang, lelang y tjepiau". La voz "medja" me parece que no se deriva del árabe sino del portugués "mesa". Así la indicación "Ar." podría ser trocada por la de "Port.". En el Suplemento (sin indicaciones) del referido Diccionario, compuesto por el sr. A. L. N. Kramer, constan "ronda, meronda, peronda y Hari Natal", igualmente de origen portugués.

Se continuará. 